Saudi Journal of Humanities and Social Sciences

Abbreviated Key Title: Saudi J Humanities Soc Sci

ISSN 2415-6256 (Print) | ISSN 2415-6248 (Online)

Scholars Middle East Publishers, Dubai, United Arab Emirates

Journal homepage: https://saudijournals.com

Review Article

\title{
Form in Beethoven's Sonata for Violin and Piano, Op. 24
}

\author{
Ceyla Ganioğlu ${ }^{1 *}$
}

${ }^{1}$ Assistant Professor, Ankara Music and Fine Arts University

\author{
DOI: $10.36348 /$ sjhss.2021.v06i02.003 $\quad$ | Received: 22.01.2021 | Accepted: 08.02.2021 | Published: 11.02 .2021 \\ *Corresponding author: Ceyla Ganioğlu

\section{Abstract}

"Spring" Op. 24 by Beethoven is one of the most famous classical sonatas for violin and piano. It can also be seen as the mirror of the composer's creative and philosophical personality. Among the 10 violin sonatas by Beethoven, the "Kreutzer" and the "Spring" are played the most. This sonata is in F Major tonality. Beethoven composed it between 1800 and 1801, and dedicated to count Moritz von Fries. One of the most notable features is that it contains many dialogues between the two instruments. Most of Beethoven's works are homo-thematic. Beethoven Sonatas are an essential part of the violin repertoire in that they challenge the players' musical and technical abilities. According to Lewis Lockwood, in his first period works as in Sonata Op. 23, piano had the biggest role. But in Op. 24 Sonata this feature had changed and the Piano and Violin have equal roles. Both instruments have melodic and thematic parts and the balance between them has an influence on the beauty of this Sonata. Before the "Spring" Sonata, Beethoven always presented the main theme in the piano. One of the most visible differences in this Sonata is that the main theme is presented by the Violin. He composed also one more movement named "Scherzo and Trio" and made a 4 movement Sonata. This Sonata could also be seen as a role model to Op. 30 No. 1 C Minor Violin Sonata and Op. 69 A Major Violoncello Sonata. According to the Beethoven biographer Wilhelm von Lenz, Beethoven's creative periods can be divided into three: First period shows influences by Mozart and Haydn in musical form, harmony and tonal relationships. Middle period is most commonly referred as "escape" because he was searching for a way to escape from Haydn and Mozart's styles. Op.24 Spring Sonata is between first and middle period of his works. Because of this, Spring Sonata has effects of new techniques but still has Mozart influences. According to Lewis Lockwood, Beethoven wanted to create extraordinary elements of beauty in this Sonata, so he used special techniques of his previous works as well as other composers $\left[^{1}\right]$. This sonata and some of his other works show Beethoven's love to his country and to the beauty of nature. Many researchers have not found information about the name of this Sonata. Lewis Lockwood said that people started to use this name in 1860s. According to him this name "Spring" is the most suitable one to show elegant melodic structure. Keywords: Beethoven-Violin- Sonata- Spring- Analysis- Form- Piano- Accompaniment- Composition- TechnicalClassical.

Copyright ( 2021 The Author(s): This is an open-access article distributed under the terms of the Creative Commons Attribution 4.0 International License (CC BY-NC 4.0) which permits unrestricted use, distribution, and reproduction in any medium for non-commercial use provided the original author and source are credited.

\footnotetext{
${ }^{1}$ Lewis Lockwood \& Mark Kroll, The Beethoven: Violin Sonatas: History, Criticism, Performance, University of Illinois Press, 2004 - pg.89
}

Citation: Ceyla Ganioğlu (2021). Form in Beethoven's Sonata for Violin and Piano, Op. 24. Saudi J. Humanities Soc Sci, 6(2) 48-52. 
1. Form

2. First movement - detailed analysis

Exposition is between measures 1-86. There is no introduction, i.e. main theme begins directly in home key $\mathrm{F}$ major. It lasts until measure 10 ending with
Perfect Authentic Cadence. It can be considered as a sentence. I.e. measures $1-10$, the theme is presented with the violin while the piano is accompanying with arpeggiated chords. In general it is an attractive theme with longwinded contour and lyrical qualities.

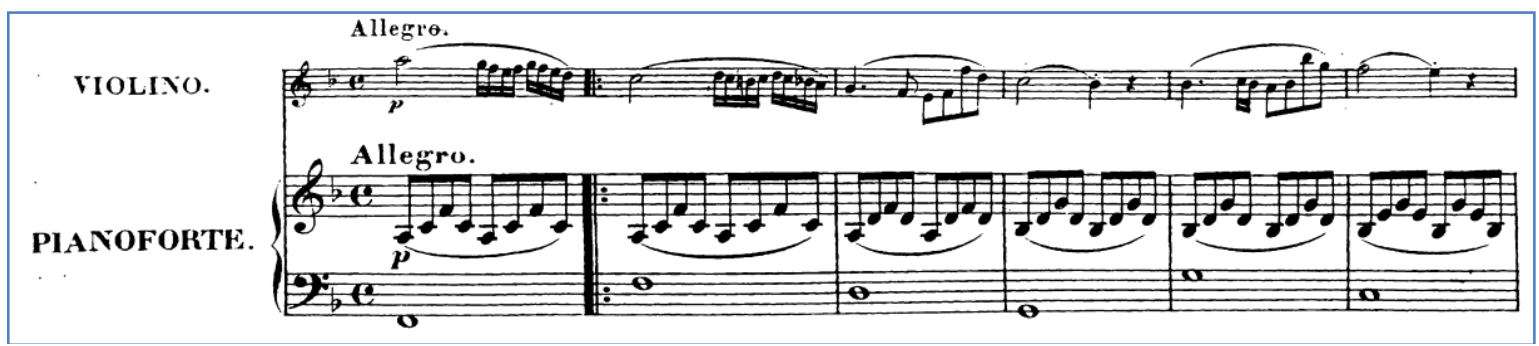

Presentation phrase has following formal functions according to Caplin: mm. 1-4: presentation $\mathrm{mm}$. 1-: basic idea mm.2-: repetition of the basic idea $\mathrm{mm}$. 1-2: tonic prolongation throughout the presentation mm. 3-10: continuation

$\mathrm{mm}$. 3-8 fragmentation (in three sections, mm. 3-4 model, mm. 5-6 and mm. 7-8

sequences; second sequence slightly modified leading to cadential)

mm. 9-10 cadential

mm. 10 ending with $P A C$ and then a lead-in to the next phrase, which helps maintain rhythmic activity

Transition begins in measure 11 with a repetition of the main theme. It could also be seen as an enlarged

Reversed Period, i.e. a consequent (mm. 1-10) followed by an antecedent (11-25).

In mm. 11-25 primary theme is repeated that leads to a $\mathrm{HC}$ (m. 21) and as a result there is a standing on the dominant (mm. 21-25):

mm. 13-18: fragmentation (in three sections as in the first exposition of the theme, mm. 13-14 model, mm. 15-16 and mm. 17-18 sequences; both embellished in piano part; second sequence further modified in $\mathrm{m}$. 18 to lead to cadential) mm. 20-21: cadential (HC)

mm. 21-25: standing on the dominant in several two measure segments as in former fragmentations $\mathrm{mm}$ 25: I:HC, MC is declined, i.e. "MC-effect" but declined

Then there is further- and more characteristic transitional activity. In measure 26 second part of Transition begins with chromatic mediant scale in $\mathrm{Ab}$ major (bVI-bIII).

This passage is a New Idea. It is modulating transition. Relation between $\mathrm{C}$ major and As major could be called as chromatic mediant, and this modulation is unexpected for Transition. This part is relatively long and lasts until measure 37. C major is heard relatively late.

mm 26-28: Chromatic mediant scale- Ab major : New Idea

mm 29-30: continuation (model in V)

mm 31-32: sequence (in i)

mm 33-34: cadential ( Ger+6 and $\mathrm{V}=\mathrm{HC}$ ) standing on the dominant and $V: H C M C$.

With chromatic passages in c minor, transition goes to its parallel major "C major" (of F major) and subordinate theme starts.

Subordinate theme is between measures 38-70. Character is different than the main theme, so could be heard slightly faster. While main theme is heard as a beautiful spring, subordinate theme is voice of energetic spring. This part consists of 32 measures and could be divided in 16 measured 2 groups.

mm 38-45: basic idea

mm 46-47 : sequenzen

mm 48-49: sequenzen

$\mathrm{mm}$ 50-51: sequenzen (ended in new tonality $\mathrm{C}$ major)

Artiqulation is also opposite to main theme. In addition, sforzando artiqulations, which come in weak beat, attracts attention. Subordinate theme ends with Perfect Autantic Cadans in measure 69.

Closing section consists of 2 parts.

First part mm 70: It is tonal prolongation part, which lasts until measure 77.

Second part $\mathrm{mm} 78-86$

Development is between measures 86-123 and in A major. It consists of Pre-Core and Core with fragmentation section.

Pre-core mm 86-97

mm 86-89 : pre-worked main theme

mm 90-97 : pre-worked subordinate theme. (in measure 89 melody comes from Beethoven Violin Concerto) 
After this introduction Core starts. mm 98-101 : model

This model is followed by fragmantation part. In this part rythm comes from subordinate theme while triplets are in loose stucture (transition and closing section motive). Tonality changes every 3 measures;

mm. 98-101 Bb major - f minor's Dominant mm. 102-105 f minor-c minor's Dominant mm. 106-109 c minor-g minor's Dominant mm. 110-113 g minor- d minor's Dominant

'The Development ends with V/VI which resolves directly to $I$ at the begining of the recapitulation. The potentially offensive cross-relation of $C \#$ in (V/VI) and Cnatural (in I) is avoided by the reduction in texture just before the recaputilation.' Caplin ( pg 141)

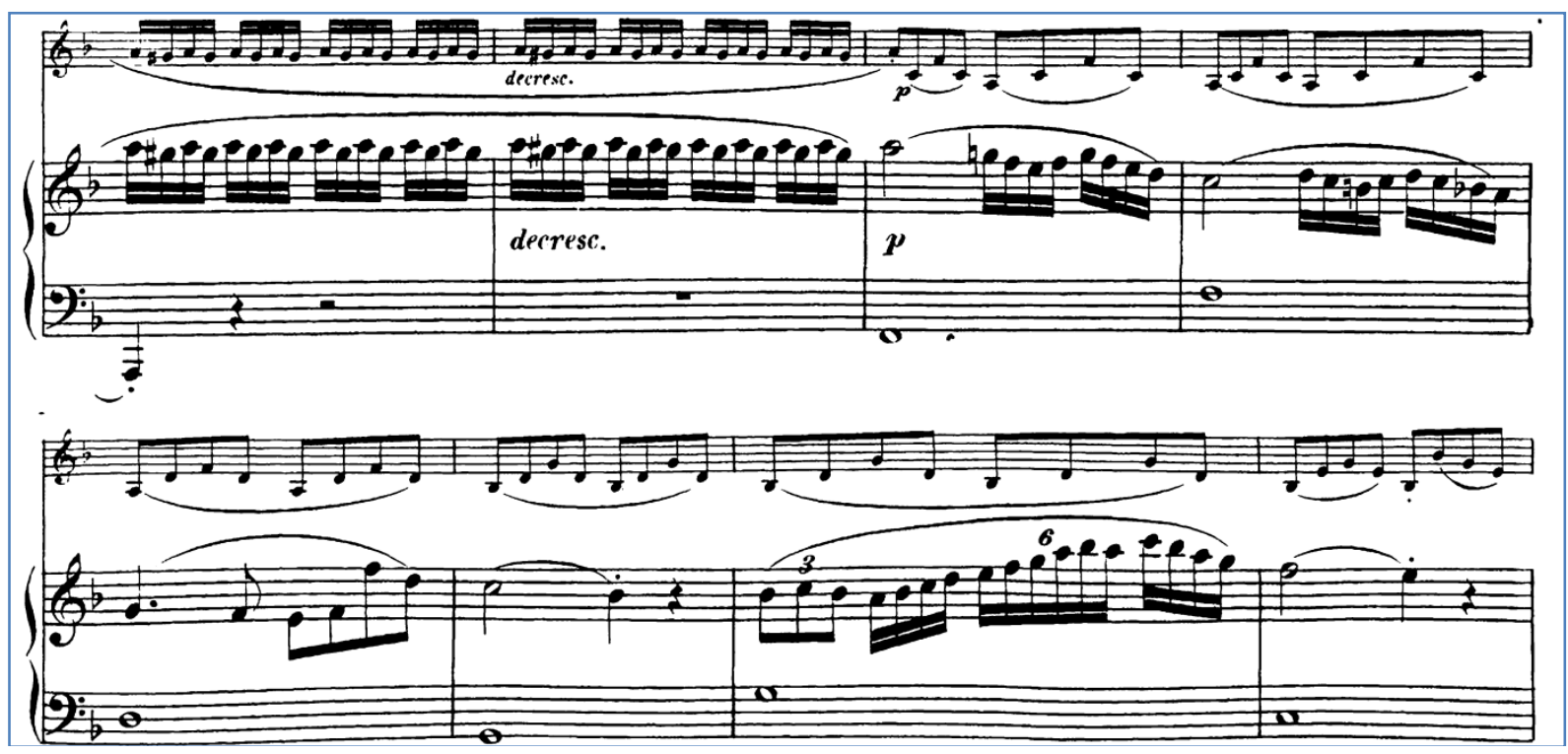

Recaputilation is between measures 124-210. It is similar to exposition. Main theme presented in Piano and Violin accompanies with eight notes.

Coda starts in measure 210 in D major. In measure 213 tonality changes to Es major and then in 218. measure to As major. It comes from Development section and ends in measure 232 with Perfect Authentic Cadans. In measure 222 Codetta starts. Last part lasts 16 measures in $\mathrm{F}$ major. In this part triplets (which comes from development) had used with main theme.

\section{i. Formal outline of the First Movement Exposition}

A theme// F-Major>C-Major // 25 Measures

Transition // As-Major>C-Major // 12 Measures

B theme // C-Major// 32 Measures

Codetta // C-Major// 17 Measures

\section{Development}

A theme // A-Major // 3 Measures

B theme // B-Major >C-Major // 8 Measures

New theme // C-Major>A-Major // 18 Measures

A-theme // A-Major>C-Major // 8 Measures

\section{Recapitulation}

A theme // F-Major>f-minor>C-Major // 26 Measures

Transition // C-Major>F-Major // 12 Measures

B theme // F-Major>f-minor>F-Major // 48 Measures
CODA // F-Major// 38 Measures

\section{b. Second movement - Adagio molto espressivo}

It is ABACA+codetta and in Rondo form. Main theme is presented by Piano in 17. measures and accompanied by sixteeenth notes. As from 10. measure Violin begins by using the same material. Between 18 . And 28. measures 1. episode starts by using a new material technigues and this term has wided.

In 38. measure Violin starts to second episode by Tonik minor (bb-minor). Accompaniment motive was formed from sixteenth notes and tonallity goes through Db-Major, gb-minor, f\#-minor (harmonick modulation), D-Major, d-minor and before last two measues if finished by Bb-Major. Violin and Piano play with main theme by ornaments in between these tonal changes. Codetta starts with tremola effect in both instruments and could be heard as Cadans. In last 3 measures of Codetta for completeness Beethoven used ornamented main theme.

\section{i. Formal outline of the Second Movement}

Main Theme // Bb-Major // 17 Measures

1. Episode // Bb-Major $>$ F-Major $>$ Bb-Major // 11 Measures

Theme // Bb-Major // 8 Measures 
2. Episode // Bb-Major $>$ Db-Major $>$ gb-minor $>$ f\#-minor $>$ D-Major $>$ d-minor $>$ Bb-Major // 17 Measures

Theme // Bb-Major >c-minor >bb-minor // 11 Measures

Codetta // Eb-Major >Bb-Major // 9 Measures

\section{c. Third movement - Allegro molto scherzo}

This cheerful and ironic movement shows Beethoven's musical intelligence and has composed in F-Major 'Scherzo'. A ruden is typical Scherzo with repetitive structure (to make it he added 'La prima porte senza repetizione'" term).

After Piano's 8 measures opening theme Violin has the same theme with rytmical dialogues in one Octava above. Repetition is also in 8 measures and in symmetrical structure. Last part of Scherzo part is in 3 measures closing melody.

Trio, in F-Major tonality consist of 8 measures and from 2 parts. It looks mostly as early classic music form. This part starts with sequent three note groups which are in eights and going up in third intervals. Last 4 measures are consist of; V7/II-II-V-I degrees and makes a Cadans. At the end is Da Capo.

\section{d. Fourth movement - Allegro ma non troppo}

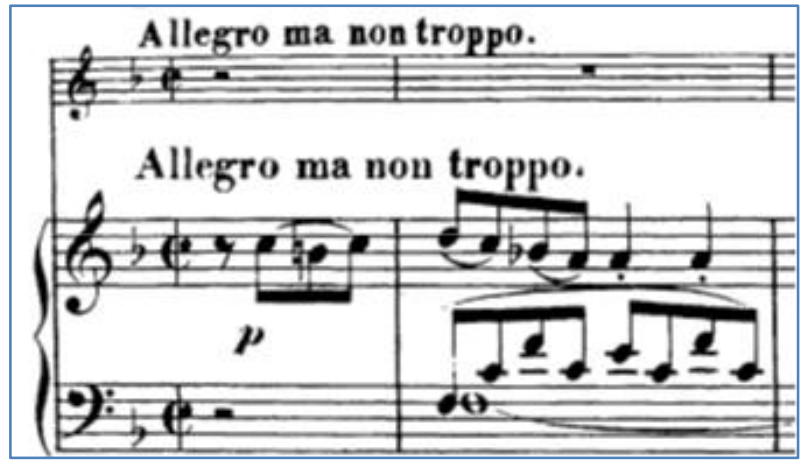

In the finale of Beethoven's Spring Sonata, he uses a Rondo-Sonata form instead of the traditional form (ABACAB1A+Coda). This movement is dance music that composed in sebare rytm and very ellegant as well as really fluent.

In A part first theme is played by piano followed by violin. Both times there are different accompaniment motive. 1. Episod is between 18. and 55. measures and the melody of 1. Episod comes from the 2 . measure of the main theme.

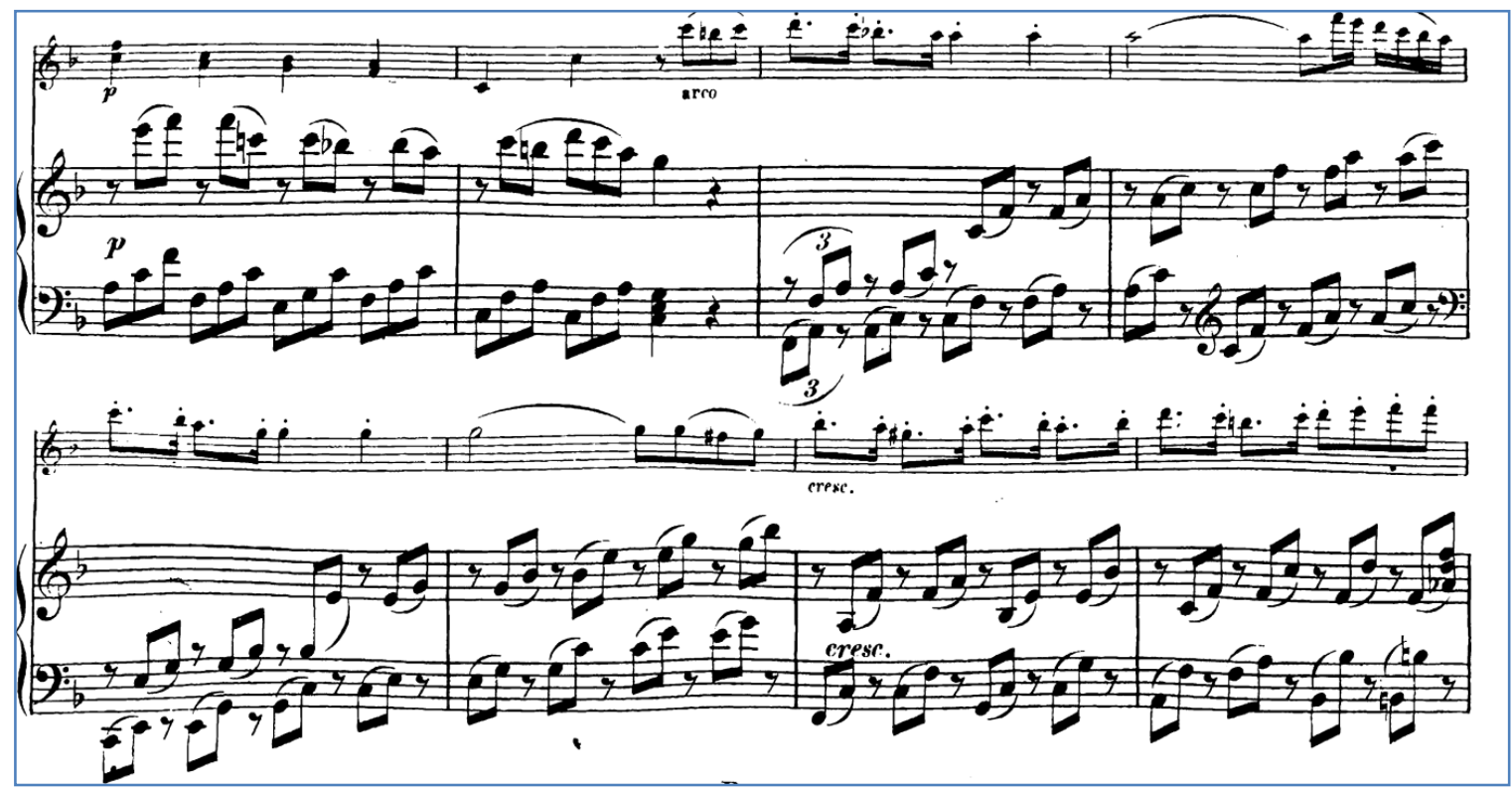

Thema of the 1. Episod played by Violin and followed by Piano. For variations triplets had used. In the 2. Episod (73. and 111. measures same material had used (in Piano) and for accompaniment Beethoven used triplet motive that has heard in last part of the 1 . Episode. When thema comes for the third time, the tonality of thema changes to D-Major and accompaniment changes. In second half (113. measure) tonality comes back to F-Major.
To make more pure sound Violin accompanies with Pizzicato effect between 125. and 130. measures. When the Violin plays the main theme, the Piano accompanies with virtousic triples.

In the repetition of the 1 . Episode, same materials are used in paralel moll tonality(f-minor). Between 197. and 205. measures Final theme comes with variable melody and rythm. 


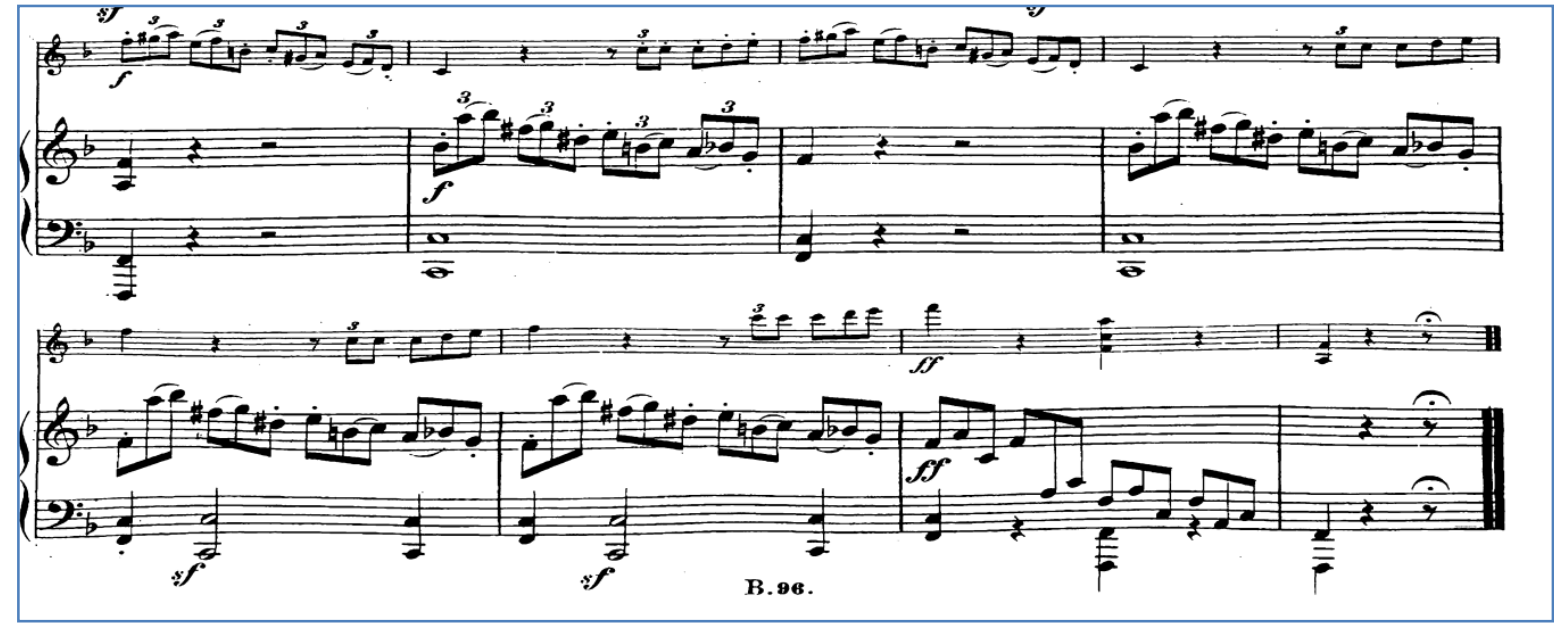

After 206. measure to the end there is a CODA. This part has a new melodic materrial. But accompaniment motive stays the same as before, triplets. In 224. measure people can hear one part from the main theme. Starting from 236. measure till the end Violin and Piano play triples (question-answer motive).

\subsubsection{Formal outline of the Fourth Movement}

Main Theme //F-Major // 17 Measures

1. Episod // F-Major >c-minor $>$ C-Major $>$ cminor>C-Major // 33 Measures

Theme // F-Major// 17 Measures

2. Episod // F-Major>D-Major // 51 Measures

Theme // F-Major // 17 Measures

1. Episod (recapitulation) // F-Major $>\mathrm{f}-$

minor $>$ eb-minor $>$ Eb-Major-eb-minor $>$ Eb-Major// 48

Measures

Theme // F-Major //17 Measures

Coda // F-Major // 38 Measures

\section{CONCLUSION}

Beethoven's Op.24 F-Major 'spring', Sonata has elements of Mozart and Haydn. It looks similar to them. By musical form, writing style, tonal connections and Violin-Piano relations. On the other hand,
Beethoven made many differences and innovations in this Sonata. He composed a short comical Scherzo movement and it has changed to typical Rondo form in the finale movement. This Sonata is composed just a year before he wrote Heiligen Statement. He used typical Beethoven terms also. As an example, Sforzandos in weak beats.

\section{REFERENCE}

1. Sposobin, I.V. (1980). Musical Form, Muzıka Press, Moskova.

2. Lockwood, L., \& Kroll, M. (2004). The Beethoven violin sonatas: history, criticism, performance. University of Illinois Press.

3. Rostal, M., Ludwig, G., \& Rolland, P. (1985). Beethoven, the Sonatas for Piano and Violin: Thoughts on Their Interpretation. Toccata Press.

4. Hepokoski, J.W. (2011). Darcy, Elements of Sonata Theory, Oxford University Press.

5. Caplin, W.E. (1998). Classical Form, Oxford University Press.

6. Szigeti, J. (1965). The Ten Beethoven Sonatas,USA. 